\title{
THE NEOTROPICAL SPECIES OF THE ANT GENUS STRUMIGENYS FR. SMITH: MISCELLANEOUS CONCLUDING STUDIES
}

\author{
By William L. Brown, JR. \\ Department of Entomology, Cornell University
}

This paper is a continuation of my series on the New World fauna of the dacetine ant genus Strumigenys Fr. Smith. Earlier parts, containing keys to the abbreviations for measurements and proportions, may be found in Jour. New York Ent. Soc. 6I: 53-59, IOI-I IO (1953). In addition to these, other parts have been published in the same journal, in Psyche, and in Studia Entomologica, Petrópolis, Brazil. This section is a final one so far as currently available material in the genus indicates; only one more section, which will be composed chiefly of an illustrated key to the New World members of the genus, is planned at present.

\section{S. micretes and S. lacacoca}

Following the descriptions of what I called the emeryi group (Brown, 1959) the species were discussed as follows:

"The four species emeryi, nevermanni, micretes and lacacoca are very close, and seem, from the limited material available, to replace one another in a chain extending from Mexico to Panama, and perhaps beyond. So far as I can see now, the differences are complex enough and strong enough to indicate that each form is a distinct species; perhaps together [they constitute] one superspecies. However, it is not beyond possibility that one or more of these forms intergrades with a neighbor. More material is needed."

Since that writing, material has turned up which, though small in amount, tends to bridge the gap between $S$. micretes Brown and $S$. lacacoca Brown, indicating perhaps that they belong to a single variable species. Nevertheless, the new material poses certain problems itself, and the discussion next offered is intended to give details that should help in eventually straightening this complex out.

A sample consisting of parts of four nest series from Boquete, Chiriqui Province, Panama (F. M. Gaige leg., see below) contains 25 workers with highly variable preapical mandibular dentition, the denticles varying in number from I to 4 in the two mandibles taken together, and also varying markedly in size, acuteness and position, so as to bridge virtually completely the chief diagnostic character-gap between micretes (each mandible with a small but acute preapical tooth, and a little farther up a minute denticle) and lacacoca (man- 
dibles completely without teeth or denticles basad of the apical fork in the preapical region). This sample indicates that the preapical dentition, usually so constant in species of Strumigenys, may sometimes be unreliable. The Boquete sample would clearly indicate synonymy between micretes and lacacoca were it not for one disturbing fact: the Boquete sample differs from the available samples of both species in its larger size and in having the promesonotum very distinctly and closely longitudinally striate throughout (arched striate along the anterior pronotal margin). This sculpture is somewhat shining, especially on the sides, where a large section becomes smooth or nearly so. The rest of the sides of the alitrunk are also smooth and shining for the most part. Postpetiole predominantly smooth and shining, crossed by a few longitudinal costulae. Propodeal teeth also longer, more slender and more nearly horizontal than in the micretes or lacacoca type series. Anterior coxae smooth or nearly so, shining.

Some specimens of micretes and lacacoca have feebly indicated longitudinal rugulae or costulae on the pronotum (in addition to the median carinula), but in these the predominant sculpture is the usual opaque reticulo-punctulation over at least the discal portion. The size, head width and sculptural traits of the Boquete sample could well be diagnostic of still another species in this close-knit complex, or they could merely mark a local population of a single variable species that would also include the types of micretes and lacacoca. For the present, it seems wise to avoid introducing new species names for members of this complex and also to hold off from synonymizing micretes and lacacoca until the distribution and variation of the complex are better known. For the convenience of future workers, I list here the material of the complex that I have studied, with such measurements, proportions and other observations as I have obtained from them $(\mathrm{n}=$ number of workers measured for each sample) :

Colombiana Farm, Santa Clara, Costa Rica (W. M. Mann leg.), TL 2.9-3.I, ML 0.70-0.74, ML 0.45-0.47, WL 0.72-0.76 mm; CI 7I-74, MI 62-65 $(\mathrm{n}=\mathrm{I2})$, type series of $S$. micretes. Progreso, Chiriqui Prov., Panama, (F. M. Gaige leg., no. 332), TL 3.I-3.3, HL $0.75-0.76$, ML 0.50-0.5 I mm; CI "about as in the type series" of micretes, MI 66-68 ( $\mathrm{n}=6)$, series placed with micretes in the original description of that species. Boquete, Chiriqui Prov., Panama (F. M. Gaige leg., nos. 208, 497, 504 and one series with no number) TL 3.7-4.0, HL 0.86-0.90, HW 0.66-0.68, ML 0.58-0.6I, WL 0.92$0.99 \mathrm{~mm}$; CI 75-76, MI 67-68 $(\mathrm{n}=25)$, Strumigenys near micretes, discussed above. Cerro Campana, west of Chorrera, Panama Prov., Panama, at about $950 \mathrm{~m}$ altitude in montane rain forest (cloud for- 
est), in rotten wood (G. B. Fairchild and $W$. L. Brown leg., no. B-86), TL 3.3, HL 0.76, HW 0.52, ML 0.53, WL $0.82 \mathrm{~mm}$; CI $68, \operatorname{MI} 70(\mathrm{n}=\mathrm{I})$, specimen here placed as $S$. lacacoca; this worker has a single extremely minute denticle in the preapical concavity of the left mandible, perhaps representing a vestige of a distal preapical tooth. Rio Chinillo, Panama Canal Zone (T. E. Snyder leg.), TL 2.8-3.2, HL 0.70-0.75, ML 0.45-0.48, WL 0.72-0.75 mm; CI 67-7 I, MI 6o-66 $(\mathrm{n}=7)$, type series of $S$. lacacoca.

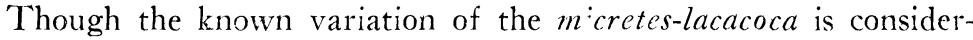
ably expanded by the new material reported above, this variation is mainly away from the direction of $S$. nevermanni Brown, from Costa Rica, a species that is generally smaller, with a relatively shorter head and mandibles and narrow infradental lamellae.

A new species of the Tococae group

Strumigenys fairchildi new species

Holotype worker: TL 4.I, HL 0.96, HW 0.72, ML 0.59, WL I.OI, scape L $0.68 \mathrm{~mm}$; CI 75, MI 6I.

Aside from its larger size and relatively longer mandibles, this species closely resembles $S$. tococae Wheeler from the Amazon Basin. The upper propodeal teeth are somewhat longer (about as long as the distance between the centers of their bases, and about twice as long as the lower teeth), and the lamella between the upper and lower teeth is lower and more cariniform. The eyes are about the same size (greatest diameter about $0.14 \mathrm{~mm}$ ), and the petiole and postpetiole are similar, but with slightly less voluminous spongiform appendages. The best distinction lies in the sculpture and pilosity of the nodes and gastric dorsum:

( I) Postpetiolar disc convex, evenly reticulo-punctulate, with only feeble anterior traces of longitudinal costulae. First gastric tergite finely longitudinally striolate, opaque-sericeous throughout (in $S$. tococae, the gaster is costulate at the base, but otherwise smooth and shining).

(2) Ground pilosity strongly reduced, virtually absent on nodes and gastric dorsum (plentiful and conspicuous in $S$. tococae). Fine erect flagelliform hairs of nodes and gaster shorter and apparently fewer than in $S$. tococae.

The color is ferruginous yellow, the gaster somewhat brighter yellow than the rest of the body.

Holotype [MCZ] a unique worker from the wooded ravine next to the inn near the top of Cerro Campana, Panama Prov., Panama, I7 January, 1960, at an altitude of 800 to $850 \mathrm{~m}$ (G. B. Fairchild 
and W. L. Brown leg.). The worker was found walking on a rotten stick lying on the leaf litter on the shaded slope of the ravine; hasty search of the litter and soil nearby failed to uncover more specimens. Since the very closely related $S$. tococae was found at Belem, Brazil, nesting in foliar sacs of the plant Tococa, it is possible that $S$. fairchildi was also nesting in a plant cavity above the ground. Since the relationships of $S$. fairchildi were not recognized until it was critically examined in the laboratory, the possibility of a plant-cavity habitat was not investigated in the field.

\section{Group of $S$. lanuginosa Wheeler}

Two species, $S$. lanuginosa Wheeler and $S$. hindenburgi Forel, share a number of traits that apparently indicate a fairly close relationship between them: Mandibles lying close together at full closure, their bases sharply narrowed from the outside; apical fork moderate in length, with a single intercalary tooth; inner (masticatory) margin concave near apex, the concavity with a short but acute preapical tooth ( $S$. hindenburgi has an additional minute denticle near the apical third of the margin). Clypeus broadly triangular, with convex anterior margin. Antennal scape slender, tapered toward both ends, very slightly curved at basal third.

Pronotum with humeral angles developed, bluntly tuberculate; anterior margin present (weak in $S$. lanuginosa); alitrunk in side view with convex dorsal profile, broken only at the impressed metanotal groove. Propodeal teeth of modest size, but acute, each subtended by a low, concave infradental lamella ending in a ventral convexity. Petiole distinctly pedunculate and with a short, dorsally rounded node; postpetiolar disc convex; both nodes with complete and welldeveloped spongiform appendages. Gaster normal in form, with a strong anterodorsal spongiform margin and a thick anteroventral spongiform pad; basigastric costulae well developed.

Head, alitrunk and both nodes densely and finely reticulo-punctulate, opaque; postpetiolar disc usually with weak rugulosity or costulation superimposed. Underside of gaster smooth and shining; mandibles weakly shining in some lights, punctulate; legs and antennae finely and densely punctulate. Sides of pronotum, anterolateral surfaces of anterior coxae, and lower lateral surfaces of infradental lamellae of propodeum with patches of fine reclinate hairs and frequently encrusted with whitish material; apparently these represent secretory areas.

Ground pilosity of head, promesonotum, posterior propodeum, scapes and legs consisting of fine, abundant reclinate and arched-reclin- 
ate hairs. Larger specialized hairs all fine, long, flagelliform, more or less erect: a pair on each lateral occipital border ( 2 pairs in lanuginosa), a pair on the middle occiput, a pair on the humeri and another pair on the mesonotum. Both nodes and both upper and lower surfaces of the gaster with a luxuriant growth of abundant, long, fine flagelliform hairs, the longest of which, on the gastric dorsum, are as long as or longer than the petiole. Each inner mandibular border bears a row of fine oblique sensory hairs.

Males of neither species have yet been found. S. lanuginosa occurs in Central America and southern Mexico, and has apparently been introduced into the Bahamas, while $S$. hindenburgi is known from southern Brazil and northern Argentina.

Strumigenys lanuginosa Wheeler

Strumigenys lanuginosa Wheeler, 1905, Bull. Amer. Mus. Nat. Hist. 21 : 104, fig. M, worker, female. Type loc.: Fort Charlotte, Nassau, Bahama Islands. Syntypes in AMNH, MCZ, several examined.

Worker: TL 2.4-2.7, HL 0.55-0.6o, ML 0.35-0.38, WL 0.58$0.64 \mathrm{~mm}$; CI 79-80, MI 63-64. Measurements from 5 workers, including a syntype, Panamanian and Mexican specimens.

Main distinguishing features:

( I) Small size and slender build.

(2) Dorsolateral borders of head merely cariniform, not lamellate.

(3) Mandibles without a trace of a denticle basad of preapical tooth.

(4) Basal costulae of gaster extended as fine, sericeous striation (striolation) over the basal third or more of the first segment. Gastric pilosity also more abundant and crowded than in $S$. hindenburgi.

(5) Two pairs of flagellate hairs on the lateral occipital margins.

(6) Postpetiole usually with traces of fine longitudinal striolation or costulation overlying the punctulation.

Color light ferruginous, gaster often slightly more brownish. Mandibles and appendages lighter, more yellowish.

Female (dealate) : TL 2.9-3.0, HL o.62-0.63, ML 0.36-0.38, WL 0.72-0.73 mm; CI 80-84, MI 57-6I (from 2 syntypes). Males unknown.

Distribution: Southern Mexico, Panama; in Bahamas, where probably introduced historically.

Localities for material examined: Bahama Islands, Nassau (W. M. Wheeler leg.), type locality. Mexico, Veracruz: Cordoba (C. H. Seevers leg.), one worker under stone. Pueblo Nuevo, near Tetzonapa (E. O. Wilson leg.), strays from leaf litter in tropical evergreen for- 
est, and foraging on surface of $\log$ in degraded rain forest. Panama Canal Zone: Barro Colorado Island (J. Zetek leg.), a single worker. This species is here reported from the American mainland for the first time; apparently it is widespread.

\section{Strumigenys hindenburgi Forel}

Strumigenys Hindenburgi Forel, 1915, Bull. Soc. Vaud. Sci. Nat., 50: 357, worker. Type loc.: "Argentine," La Plata from label on syntypes. Syntypes in Coll. Forel, Museum d'Histoire Naturelle, Geneva, and MCZ, several examined.

Strumigenys hindenburgi, Kempf, 1958, Stud. Ent. (n.s.) 1:555, record from $10 \mathrm{~km} \mathrm{sw}$ of Agudos, S. Paulo State, Brazil, among dry leaves in wooded gully.

Worker: TL 2.8-3.2, HL o.60-0.69, ML 0.38-0.40, WL 0.63-0.7 I $\mathrm{mm}$; CI 83-88, MI 58-64. Measurements from 3 syntypes and 6 additional Argentinian specimens representing 3 nest series.

Within the lanuginosa group, this species is distinguished by its large size and relatively broad head, as well as the following characters:

( I) Dorsolateral borders of the head (dorsal scrobe borders) on each side produced as a narrow but distinct lamellar margin that gradually narrows posteriad and ends in a shallow concavity behind the level of the eye.

(2) Mandibles each with an extra minute preapical denticle, best seen in oblique view in dark silhouette against a bright background, near the apical third of the shaft.

(3) Basigastric costulae extending less than half the length of the first segment, the rest of which is smooth and shining.

(4) Lateral occipital margins each with only one flagellate hair, arising from the concavity at the end of the lamellate dorsolateral margin.

(5) Occiput, pronotum and postpetiolar disc with traces of feeble reticulate rugulation superimposed on the basic dens:ly punctulate sculpture.

Color medium ferruginous; legs, mandibles and antennae more yellowish; gaster mostly brown.

Pseudogyne or ergatoid female from Itatiaia: TL 2.7, HL o.6o, HW 0.49, ML 0.34, WL $0.60 \mathrm{~mm}$; CI 82, MI 57. This small individual has the mesonotum developed in the direction of the full female, with raised margins dorsad, and the differentiated scutellum acutely projecting posteriad. The petiolar and postpetiolar nodes are wide, as expected in females of this genus, but the gaster is not unusually bulky for a worker. A tiny apparent remnant of a median ocellus occurs in the central vertex. This specimen appears to me to 
be classifiable as a pseudogyne, or pathological worker-female intermediate.

Distribution: Northern Argentina, extending into southeastern Brazil.

Localities for material examined: Argentina: La Plata (C. Bruch leg.), 3 syntypes. Salinas, near Tucumán (Kusnezov and Golbach leg., no. 1677). Parque Avellanida, Tucumán (P. Wygodzinsky leg.), a small series of workers. Brazil: Rio de Janeiro State, Itatiaia, Lago Azul (R. Barth leg.), the single pseudogyne described above.

\section{The Variation and Synonymy of Strumigenys louisianae Strumigenys louisianae Roger}

Strumigenys louisianae Roger, 1863, Berlin. ent. Zeitschr. 7 : 211, worker. Type loc.: "Louisiana." Type in Zoologisches Museum der Humboldt Universitä, Berlin, not examined

Sirumigenys unidentata Mayr, 1887, Verh. zool.-bot. Ges. Wien 37:575 and in key, p. 570, worker. Type loc.: "St. Catharina." Lectotype, by present designation, in Naturhistorisches Museum, Vienna, examined. NEW SYNONYMY.

Strumigenys fusca Emery, 1894, Bull. Soc. ent. ital. 26: 215, pl. 1, fig. 8, worker. Type loc.: Manicore, Amazonas. Holotype in Museo Civico di Storia Naturale, Genoa, examined. NEW SYNONYMY.

Strumigenys clasmospongia Brown, 1953, Psyche 60: 2, worker. Type loc.: Petropolis, Rio de Janeiro State, Brazil. Holotype in Coll. W. W. Kempf (ex Coll. T. Borgmeier), São Paulo, Brazil; paratypes in Coll. Kempf, USNM, MCZ, several reexamined. NEW SYNONYMY.

In my "Revisionary Studies" of 1953, I showed that $S$. louisianae is a very variable species ranging from warm temperate North America south into Bolivia and northern Argentina. However, variation at that time was thought to involve mainly body size and proportions of the head and mandibles. After prolonged study, a number of names (see synoptic synonymy below) was placed in the synonymy of $S$. louisianae; types were compared in most of these cases. The variety longicornis was also synonymized on the basis of its original description.

In another paper entitled, "Three new ants related to Strumigenys louisianae Roger" (Brown, I953a), I described S. clasmospongia, $S$. producta and $S$. mixta, stating that "each of the three forms has been compared with all other neotropical species known to me, both described and undescribed, except $S$. fusca and $S$. unidentata, two species to be placed among the species inquirendae." Since that writing, I have been able to study the (previously unavailable) types of $S$. fusca, $S$. unidentata and $\mathcal{S}$. unispinulosa var. longicornis on deposit in Vienna and Genoa, through the kindness of Dr. Max Beier and Dott. Delfa Guiglia respectively. From the first comparison, it was clear that my 
clasmospongia was only a larger, relatively narrow-headed variant of unidentata. The unique type of $S$. fusca was more puzzling, being a rather large louisianae-like worker with fairly broad head and longish mandibles, but having the posterior half of the first gastric tergite nearly completely smooth and definitely shining. Var. brevicornis turned out as expected: a large louisianae female fitting fairly well with the largest worker forms from South American samples of the species, so that my earlier synonymy was confirmed.

In addition to these types, I have been able during the last few years to examine an increasing accumulation of louisianae-related forms from southeastern Brazil and northern Argentina, and scattered specimens have even come in from central Brazil and Surinam, previously blanks on the map. These samples are due mostly to the kindness of Father Borgmeier and Father Kempf. Study of this new material has completely changed my ideas on relationships of the species within the louisianae complex. First, the relatively slender, long-mandibulate forms with shining gastric dorsum were shown to be common in southeastern Brazil; it is these forms to which the names unidentata and clasmospongia have been applied. Taken in combination, the distinctive "unidentata characters" give the impression of a distinct species inhabiting southeastern Brazil, but all attempts to define a species with these characters have failed. The reason for this failure is that the new material clearly shows that each of the characters going to make up the unidentata in its "typical" manifestation actually has its own independent pattern of geographical and individual variation within louisianae. The long mandibles (MI up to 67) of the southeastern Brazilian samples are approached by samples from Bolivia (MI 6o-63), and some series from southeastern Brazil have much shorter mandibles ( $\mathrm{MI}$ as low as 56 , and perhaps even lower in some samples seen but not measured), in this respect being not far from average for the species louisianae taken as a whole. The gastric sculpture of the unidentata pattern, in which basigastric costulae of moderate length are followed by a smooth or nearly smooth, shining surface (though this surface may be obscured by secretion or other foreign matter), is not confined to southeastern Brazilian specimens with long mandibles; in fact, it is found in series with much shorter mandibles from localities as far away as Tucuman, in northern Argentina; Goias, Amazonas and Surinam in the northwest and north; and even in southern Mexico (Veracruz, Puebla). Furthermore, certain series cven in southeastern Brazil contain workers with shorter mandibles, some individuals of which have the reticulate, opaque "louisianae sculpture", while others from the same nest sample have 
the gaster predominantly smooth and shining. Variation in the queens is poorly known because not many of the "unidentata" workers are accompanied by females in the collections I have seen. In general, louisianae-complex queens have stronger gastric sculpture than the workers accompanying them.

In view of the discordant nature of the variation in the only good distinctive characters available, I am forced to consider fusca, unidentata, and clasmospongia as synonyms of louisianae. It is possible that the variation of this very plastic species is even greater in central and northern South America, from which our samples are so few, and perhaps even the large, very long-mandibulate producta is only another extreme variant of louisianae. The type of fusca does show tendencies in the direction of producta, but we shall need more material from Western Brazil and Bolivia before we decide this question. Of course, the possibility must not be overlooked that louisianae really is made up of a number of cryptic species, inseparable by conventional morpholog.cal study.

A fact of continuing intersst is the absence of $S$. louisianae from the forest on Barro Colorado Island in the Panama Canal Zone. Intensive collecting by a number of myrmecologists on the Island was repeated in January 1960 by Dr. E. S. McCluskey and myself, making full use of Brrlese funnels and other modern collecting techniques, but no one has yet found $S$. louisianae on the Island or elsewhere in Panama. This is especially strange in view of the fact that the species is common in banana plantations on both the Atlantic and Pacific sides of Costa Rica near the Panama border ( $\mathrm{El} \mathrm{Palmar}$ and Coto in the Golfo Dolce, E. O. Wilson leg.). While we now have very inadequate ecological information, it does seem possible that $S$. louisianae may be a species that has adapted to habitats marginal to the rain forest of the South American continent, and that this has something to do with its present wide distribution - the widest of any New World dacetine. In this sense, S. louisianae may fit Wilson's (1959) "Stage-I" category of expanding species. It is also of interest to note that the species is much less variable ("more typical") in the North American extremities of its range than in the presumed evolutionary center in South America. Furthermore, the "typical" characteristics of short mandibles and reticulate gastric sculpture, while discordant one with the other geographically, tend to prevail at the extremities of the range in North America and South America as well, indicating a centrifugal evolution and movement of these characters.

Below I have listed some of the available samples of $\mathcal{S}$. louisianae by geographical regions, with special emphasis on some of the more 
significant South American samples reviewed since 1953, and giving certain measurements and proportions as known for the combined samples from each region $(\mathrm{n}=$ number of workers in each combined sample).

Southeastern United States (8 localities in 5 states) : HL 0.52-0.6 I, ML $0.27-0.23 \mathrm{~mm}$; CI 82-87, MI 52-57 $(\mathrm{n}=15)$. Guatemala and Costa Rica: HL 0.50-0.58, ML 0.27-0.33 mm; CI 83-85 ( $\mathrm{n}=\mathrm{II}$ ). Cuba and Puerto Rico: HL 0.52-0.6o, ML 0.26-0.32 mm; CI 83-87, MI 5I-56 $(\mathrm{n}=\mathrm{II})$. Colombia (Rio Porce and Medellin, leg. N. A. Weber) : HL 0.54-0.6I, ML 0.32-0.34 mm; CI 7I-84, MI 55-56 $(\mathrm{n}=3)$. Surinam (La Poulle and Dirkshoup, leg. I. van der Drift) : HL 0.49-0.53, ML 0.29-0.30 mm; CI 83-86, MI 57-59 $(\mathrm{n}=2)$. Goias (Anapolis, leg. W. W. Kempf) : HL o.47, ML $0.23 \mathrm{~mm}$; CI 85, MI $49(\mathrm{n}=\mathrm{I})$. Southeastern Brazil (States of Rio de Janeiro, São Paulo, Santa Catarina and Rio Grande do Sul) : HL 0.46-o.58, ML 0.28-0.37 mm; CI 77-92, MI 56-67 $(\mathrm{n}=22$ ). Bolivia (Rosario, leg. W. M. Mann) : HL 0.50-0.53, ML 0.3I-0.32 mm; CI 8I-83, MI 6o-63 $(n=6)$. Holotype female of var. longicornis from Coroico, Bolivia: TL 3.0, HL o.66, ML 0.38, WL $0.77 \mathrm{~mm}$; CI 85, MI 58. Northern Argentina (3 localities) : HL 0.49-0.64, ML 0.26-0.35 $\mathrm{mm}$; CI 83-89, MI 52-56 $(\mathrm{n}=6)$.

An additional record of interest is a sample of $S$. louisianae from Yuma, Arizona, "on cotton," "HAGA" leg.

\section{Descriptive Note on the Holotype of $S$. fusca}

Holotype worker: TL 3.4, HL 0.67, ML 0.40, WL 0.7 I mm; CI 82, MI 59. A large variant of $S$. louisianae; mandibles farther apart and relatively more slender than in North American louisianae samples; inner margins not so sharply concave near apex. Apical fork: dorsal tooth about $0.12 \mathrm{~mm}$ long, ventral about $0.09 \mathrm{~mm}$; two subequal intercalary denticles. Preapical tooth about $0.05 \mathrm{~mm}$ long, and its tip situated about $0.05 \mathrm{~mm}$ from dorsal apical tooth; slightly curved toward mandibular apex; larger and farther from apical fork than in most $S$. louisianae. No other teeth or denticles on inner mandibular border. Scape L o.44, funiculus L $0.58 \mathrm{~mm}$.

Promesonotum high, with convex profile, promesonotal suture (sulcus) visible in some lights. Metanotal groove weak. Propodeal teeth acute, elevated, with narrow infradental lamellae approaching cariniform; teeth about $4 / 5$ as long as the distance between their basal centers. Petiolar peduncle longer than node; node broader than long. Postpetiole robust, fully punctulate, opaque. Spongiform appendages as usual for $S$. louisianae. Gastric costulae extending about I/2 the 
length of the basal tergite, interspersed with reticulo-punctulation; remaining half of tergite nearly completely smooth, distinctly shining. Pilosity as usual in $S$. louisianae, but a little coarser than the average. Color dark ferruginous, but not as dark as some specimens of the "unidentata" conformation from the wet Serra do Mar, the coastal mountain strip of São Paulo; these latter samples approach black.

The fusca type is similar to producta as well as to more "typical" louisianae, but differs in details of cephalic proportions and in sculptural details. The body of the fusca type is more robust, and the hairs of the pilosity are larger throughout. The preapical tooth is larger and is situated a little farther from the apical fork.

\section{Descriptive Note on the Lectotype of S. unidentata}

Lectotype worker: TL 2.2, HL 0.55, ML 0.36, WL $0.54 \mathrm{~mm}$; CI 79, MI 66. Despite its slightly smaller size and wider head, there is little doubt that this type and the species I described as clasmospongia are conspecific. I have partially cleaned and reexamined the postpetiole and gaster in the available types of unidentata and clasmospongia, and the postpetiole is now seen to vary from weakly to moderately shining discad, while the gastric dorsum now appears as smooth and shining, with reticulation nearly or quite absent, except for the basal costulae. The frequent presence of a refractory hardened secretion (?) on the gastric dorsum is misleading when describing sculpture in a number of dacetine groups. The specimen now in the Naturhistorisches Museum in Vienna has been selected as lectotype, and is so labeled.

\section{Synoptic Synonymy of Strumigenys louisianae}

In the list below are found the names currently considered to be synonyms of $S$. louisianae. Full page references for each synonym are to be found in Brown, $1935 \mathrm{~b}, \mathrm{p} .28$, or, in the case of new synonymy, with the species heading above.

S. louisianae Roger, 1863

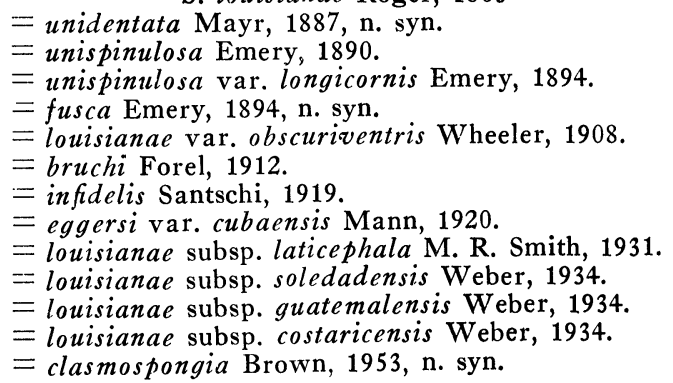




\section{References Cited}

Brown, W. L., JR.

1953a. Three new ants related to Strumigenys louisianae Roger. Psyche, $60: 1-5$.

1953b. Revisionary studies in the ant tribe Dacetini. Amer. Midl. Nat., $50: 1-137$, cf. pp. 28-31.

WILSON, E. O.

1959. The neotropical species of the ant genus Strumigenys Fr. Smith: group of emeryi Mann (Hymenoptera). Ent. News, 70: 97-104.

1959. Adaptive shift and dispersal in a tropical ant fauna. Evolution, 13 : 122-144.

A NOTE ON THE ANT GNAMPTOGENYS HARTMANI WHEELER. - Workers and winged females of this ant were received recently from Dr. M. R. Smith of the U. S. National Museum and were determined by direct comparison with the type in the Museum of Comparative Zoology. The sample represents a nest taken in the soil of a banana plantation on Zapote Farm, La Lima, Honduras, May 18, 1961 (E. Mólendez leg.). This is the first record of the species to come to light since the original description, published in 1915 , based on a single worker specimen from Huntsville, Texas (C. G. Hartman leg.). The type locality in northeastern Texas has always seemed anomalous for a genus otherwise confined to a more strictly tropical climate and not known from any other samples occurring natively within the continental United States, but until the present find, the good possibility remained that G. hartmani was an extralimital relict. It now seems more likely that the Texas record represents either a locality error or an adventive specimen taken from bananas. No ecological data accompanied the original find. At least, the occurrence of this (or other) species of Gnamptogenys in Texas remains to be convincingly demonstrated.-W. L. BRown, JR., Department of Entomology, Cornell University. 

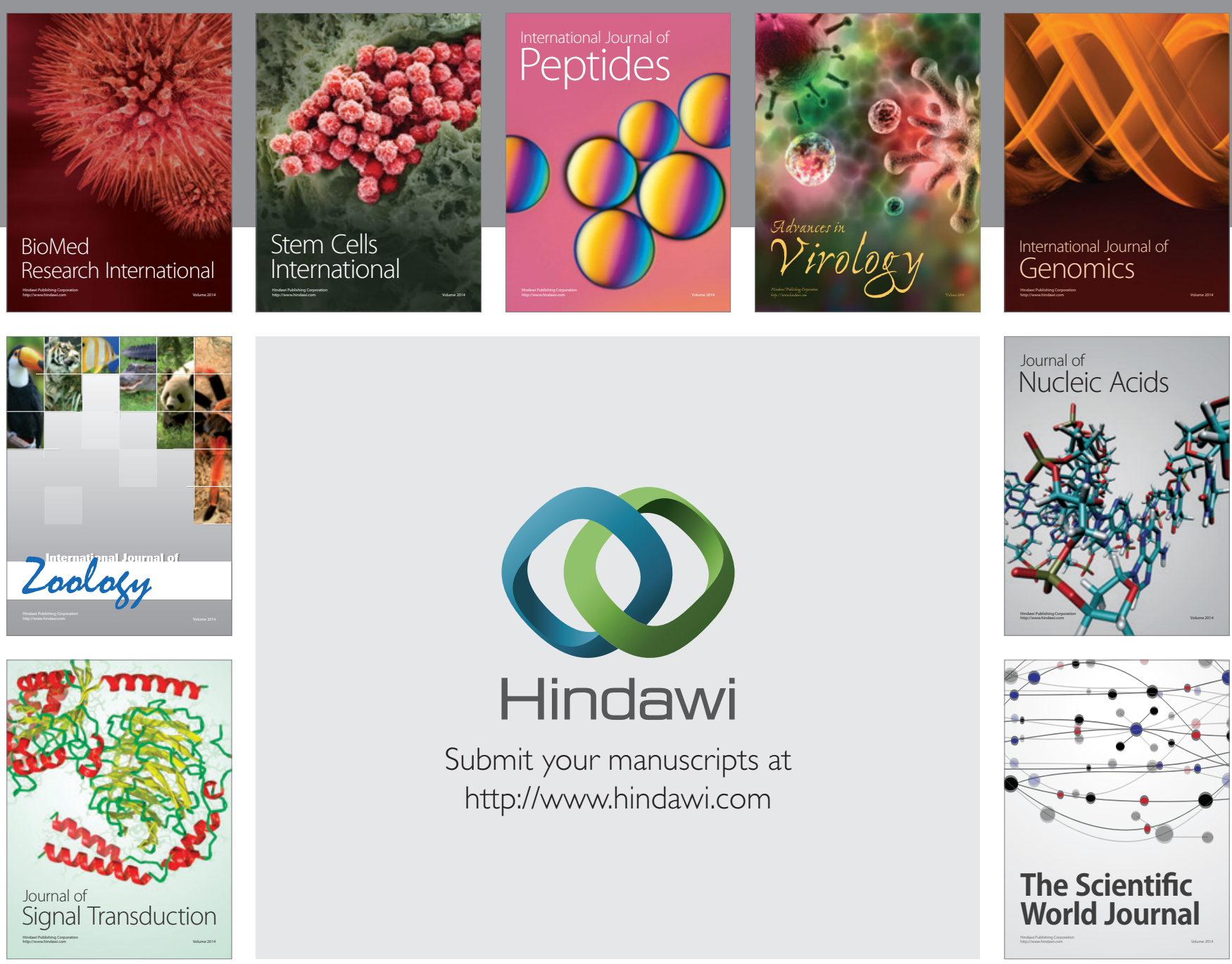

Submit your manuscripts at

http://www.hindawi.com
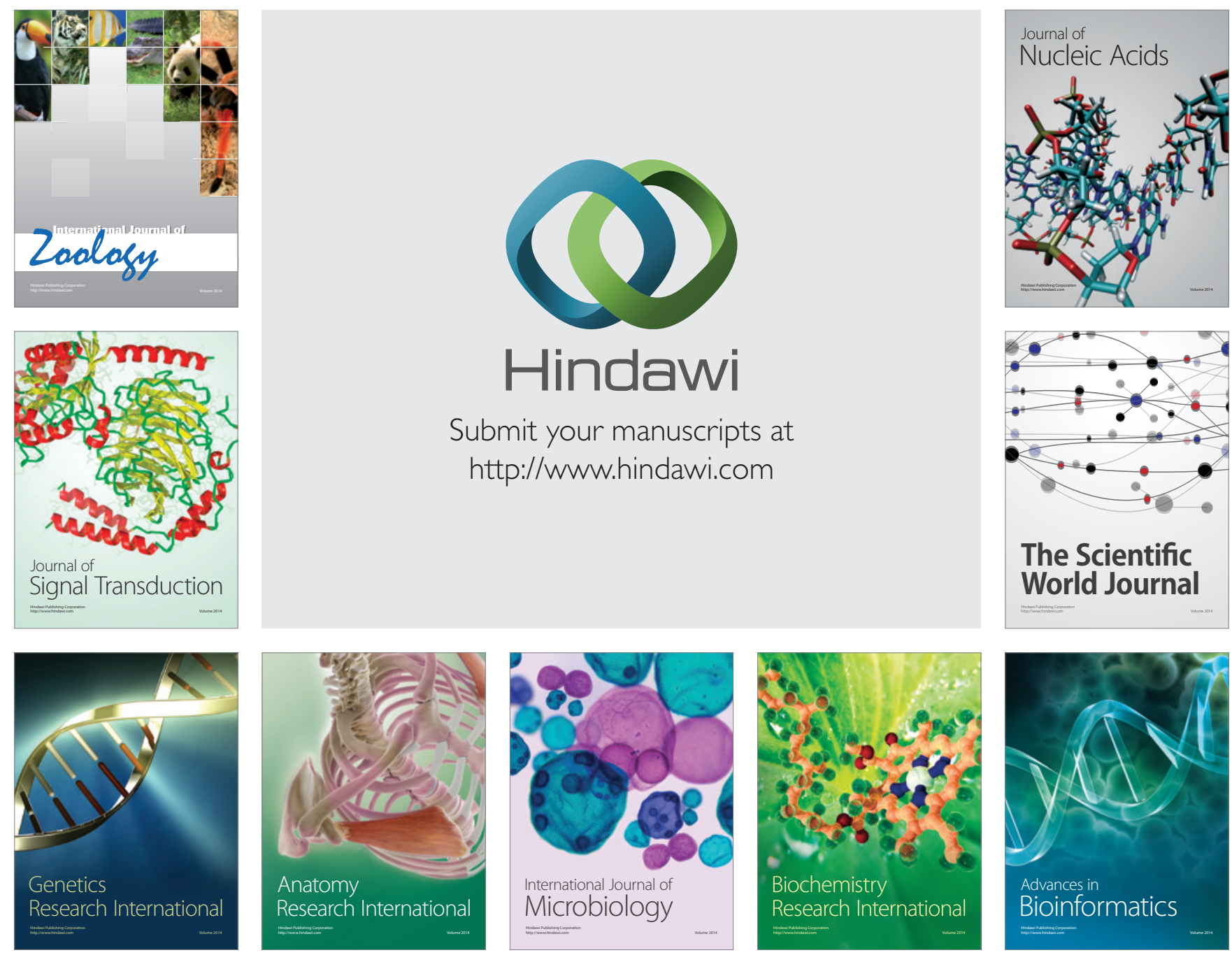

The Scientific World Journal
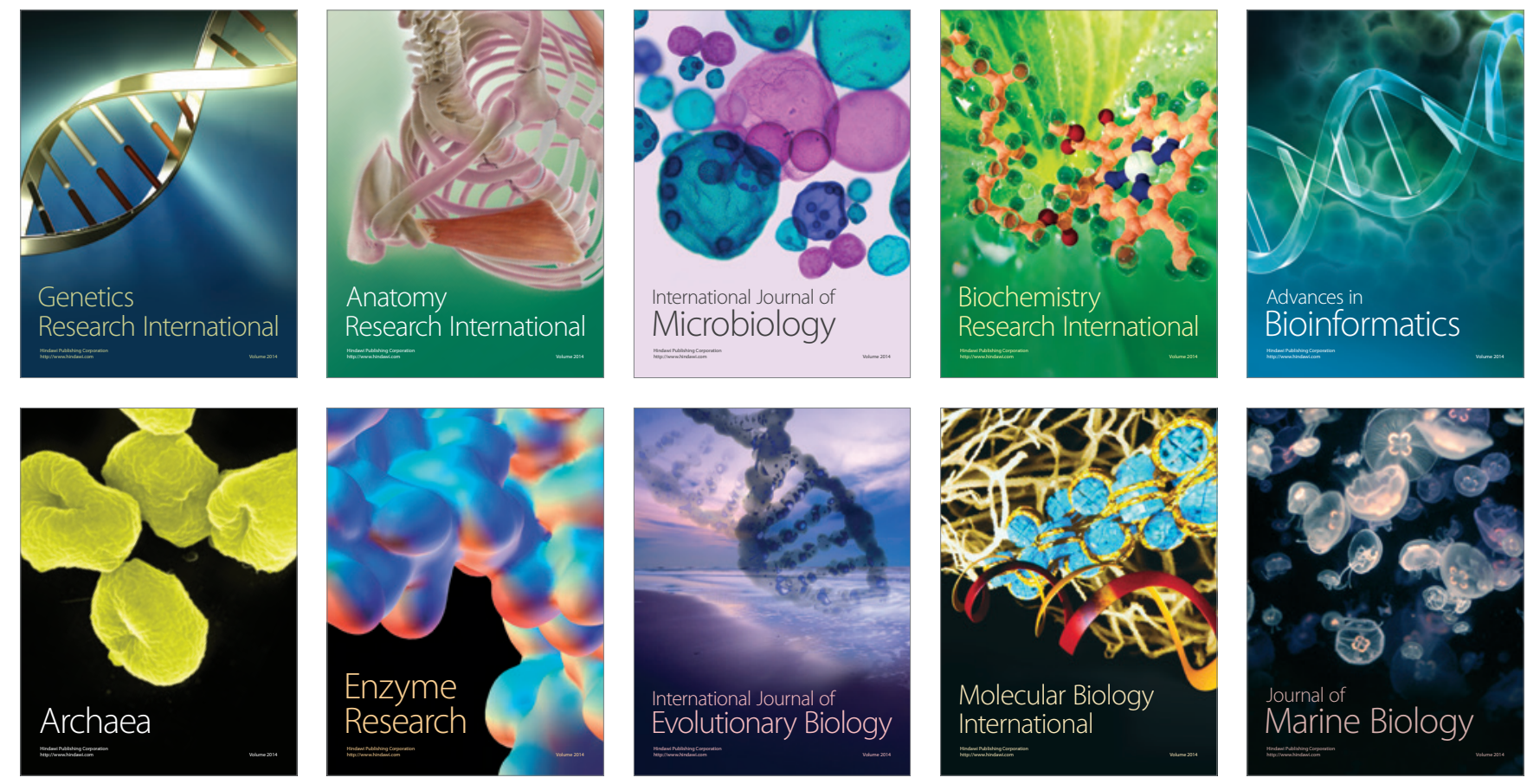